\title{
Proliferation-dependent HIV-1 Infection of Monocytes Occurs during Differentiation into Macrophages
}

\author{
Hanneke Schuitemaker, ${ }^{\star}$ Neeltje A. Kootstra, ${ }^{\star}$ Marco H. G. M. Koppelman, ${ }^{\ddagger}$ Sylvia M. Bruisten, ${ }^{\ddagger}$ \\ Han G. Huisman, ${ }^{\star}$ Matthijs Tersmette, ${ }^{*}$ and Frank Miedema* \\ Central Laboratory of the Netherlands Red Cross Blood Transfusion Service and Laboratory for Experimental \\ and Clinical Immunology of the University of Amsterdam, *Department of Clinical Viro-Immunology, \\ and ${ }^{\ddagger}$ Department of Developmental Research, Amsterdam, The Netherlands
}

\begin{abstract}
Requirements for the establishment of productive infection with the human immunodeficiency virus type 1 (HIV-1) in primary monocytes were investigated. In vitro, monocytes rendered susceptible for infection after at least a 2-d culture, but when cultured in the presence of differentiation-inducing agent IL-4, accelerated susceptibility was seen. Complete resistance to HIV-1 infection was observed in monocytes that had been treated for $5 \mathrm{~d}$ with $\mathrm{rIL}-\mathbf{4}$, and comparable results were obtained with other differentiation inducers such as dexamethasone or $1,25(\mathrm{OH})_{2}$ vitamin $\mathrm{D}_{3}\left(1,25(\mathrm{OH})_{2}\right.$ vitD $\left.\mathrm{D}_{3}\right)$. The inhibition of productive infection was not caused by downregulation of CD4 expression or HIV-1 transcription, nor by intracellular accumulation of virions. Since treatment with rIL-4, dexamethasone, or $1,25(\mathrm{OH})_{2}$ vitD $\mathrm{D}_{3}$ also resulted in complete inhibition of monocyte proliferation, we studied whether establishment of productive infection in monocytes is proliferation dependent. Irradiation or mitomycin-C treatment within $24 \mathrm{~h}$ after inoculation prevented productive HIV-1 infection of monocytes, suggesting a proliferation-dependent step early in the virus replication cycle. Polymerase chain reaction (PCR) analysis revealed the presence of only incomplete proviral DNA species in nonproliferating monocytes, indicating restriction of viral replication at the level of reverse transcription. Thus, in analogy with HIV-1 infection of CD4+ T cells, proliferation of monocytes during differentiation into macrophages is a prerequisite for productive infection with HIV. (J. Clin. Invest. 1992. 89:11541160.) Key words: HIV-1 • monocyte • proliferation • differentiation
\end{abstract}

\section{Introduction}

It is now well established that monocytotropic HIV-1 variants and cells of the monocyte/macrophage lineage play an important role in the course of HIV-1 infection (1-4). The presence of monocytotropic HIV-1 variants during all stages of HIV-1 infection $(4,5)$ suggests a role in persistence, whereas the finding that macrophages are the predominantly HIV-1-infected

Address correspondence and reprint requests to Dr. H. Schuitemaker, c/o Publication Secretariat, Central Laboratory of the Netherlands, Red Cross Blood Transfusion Service, P.O. Box 9406, 1006 AK Amsterdam, The Netherlands.

Received for publication 22 August 1991 and in revised form 18 November 1991.

J. Clin. Invest.

(C) The American Society for Clinical Investigation, Inc. 0021-9738/92/04/1154/07 \$2.00

Volume 89, April 1992, 1154-1160 cells in tissue $(1,5)$ indicates a role for these cells in dissemination of the virus. However, peripheral blood monocytes or their bone marrow precursors only seldom harbor the virus (6-8), suggesting that susceptibility to HIV-1 infection is dependent on a certain state of differentiation. Treatment of promonocytic cell lines with differentiation-inducing agents resulted in enhanced susceptibility for monocytotropic HIV-1 variants (9), and several soluble factors or cytokines that regulate HIV-1 expression have been described (10-14).

Recently, requirements for the establishment of productive HIV-1 infection in T cells were reported $(15,16)$. Normal entry of virions in quiescent $T$ cells was demonstrated, but productive infection was only established after induction of cell proliferation (15).

In this study we investigated the cellular requirements for the establishment of a productive infection in monocytes. We demonstrate that in monocytes HIV-1 infection is also replication dependent in a manner comparable to $T$ cells, and we show that induction of terminal differentiation renders monocytes refractory to HIV-1 infection.

\section{Methods}

Cell isolation and culture. Monocytes were prepared from PBMC of HIV-seronegative plasmapherese donors, as described (17), and cultured in vitro as monocyte-derived macrophages (MDM). ${ }^{1}$ In brief, PBMC were obtained from venous blood by isolation on a percoll density gradient, and the monocyte fraction was purified ( $>95 \%$ pure) by centrifugal elutriation. The virtual absence of $T$ cells in this population was demonstrated by the lack of $\left[{ }^{3} \mathrm{H}\right]$ thymidine incorporation in these cells above background levels, upon stimulation with phytohaemaglutinin. Monocytes were cultured for $5 \mathrm{~d}$ at a concentration of $10^{6}$ monocytes/ml in endotoxin-free (11) Iscove's modified Dulbecco's medium (IMDM) supplemented with $10 \%$ pooled human serum, penicillin $(100 \mathrm{U} / \mathrm{ml})$, and streptomycin $(100 \mu \mathrm{g} / \mathrm{ml})$. Cells were plated in 96 well plastic tissue culture plates (Nunc, Roskilde, Denmark) $(100 \mu \mathrm{l} /$ well), and maintained at $37^{\circ} \mathrm{C}$ in a humidified atmosphere supplemented with $5 \% \mathrm{CO}_{2}$. Cultures were kept for 2 to $3 \mathrm{wk}$, and medium was changed every $7 \mathrm{~d}$.

Virus. For cell-free infection of MDM, the monocytotropic virus HIV-1 Ba-L (a kind gift of Dr. M. Popovic, NCI, Bethesda, MD), originally obtained from a lung biopsy from a boy with HIV-1-related lymphoid interstitial pneumonia, was used. MDM cultures were infected at day 5 of culture, unless indicated otherwise. After $24 \mathrm{~h}$, unabsorbed

1. Abbreviations used in this paper: $\mathrm{CAT}$, chloramphenicol acetyltransferase; HIV-1-LTR, HIV-1 long-terminal repeat; MDM, monocytederived macrophages; $1,25(\mathrm{OH})_{2}$ vitD $_{3}, 1,25(\mathrm{OH})_{2}$ vitamin $\mathrm{D}_{3} ; \mathrm{PCR}$, polymerase chain reaction; rGM-CSF, recombinant granular macrophage-colony-stimulating factor; rTNF-alpha, recombinant tumor necrosis factor. 
virus and residual nonadherent cells were removed by washing. MDM were further cultured in the medium described above.

Virus detection. Virus production was assessed in a p24 antigen capture ELISA (18). Triton X-100-treated culture supernatant samples were added to microtiter plates (Nunc) coated with a monoclonal antibody to p24 shown to recognize all HIV isolates (18). After washing, bound p24 was detected with horseradish peroxidase-labeled antip24 rabbit IgG, followed by the addition of the substrate TMB $\left(3,5,3^{\prime}, 5^{\prime}\right.$ tetramethyl benzidine; Sigma Chemical Co., St. Louis, MO). A culture was considered positive when extinction was over two times the negative control.

Cytokines and other agents. Recombinant IL-1 $\alpha(5 \mathrm{ng} / \mathrm{ml})$ was from Hoffmann-La Roche Inc. (Nutley, NJ); LPS (Escherichia coli; 055:B5) was obtained from Sigma Chemical Co., rIL-6 was produced in $E$. coli and purified by means of affinity chromatography, followed by gel filtration (19). The specific activity of rIL-6 was $10^{9} \mathrm{U} / \mathrm{mg}$. rIL-3 $(10 \mathrm{ng} / \mathrm{ml})(20,21)$ was from Gist-brocades (Delft, the Netherlands). Recombinant IL-4 (rIL-4) $(50 \mathrm{ng} / \mathrm{ml})$, recombinant tumor necrosis factor $(\mathrm{rTNF} \alpha)(5 \mathrm{ng} / \mathrm{ml})$ and recombinant granulocyte macrophage-colony stimulating factor ( $\mathrm{rGM}-\mathrm{CSF})(100 \mathrm{U} / \mathrm{ml})$ were from Sandoz $\mathrm{Ltd}$. (Basel, Switzerland). Polyclonal antisera against rIL-4 were raised in sheep, and kindly provided to us by Dr. L. A. Aarden (Department of Autoimmune Diseases, CLB, Amsterdam). For both the transfection experiments and the virus production experiments, monocytes were cultured for $5 \mathrm{~d}$ before infection or transfection in the presence of the cytokines to be tested.

To analyze the effect of mitomycin-C or irradiation, cells were cultured for $5 \mathrm{~d}$ in the absence or presence of rIL-3 or rGM-CSF. $30 \mathrm{~min}$ before infection with HIV-1, or $3,6,12,24$, or $48 \mathrm{~h}$ after inoculation, cultures were treated with mitomycin-C $(200 \mu \mathrm{g} / \mathrm{ml})$ (Janssen Pharmaceutica, Beerse, Belgium) or irradiated (5,000 rad). After a 30-min mitomycin-C treatment, cells were thoroughly washed.

$R N A$ isolation and Northern blot analysis. MDM cultured for $5 \mathrm{~d}$ in the presence of the cytokine to be tested were harvested. Total RNA of $50 \times 10^{6}$ cells/treatment was extracted with $4 \mathrm{M}$ guanidine isothiocyanate, followed by centrifugation in $5.7 \mathrm{M} \mathrm{CsCl}$. Total RNA from 25 $\times 10^{6}$ was separated on a $1 \%$ agarose-formaldehyde gel, and transferred to Gene-screen Plus membranes (Du Pont Co. Diagnostic and Biosearch Systems, Wilmington, DE). Hybridizations were performed with probes radiolabeled by the random primer method.

Transfection and CAT assays. Primary MDM were transfected, using the electroporation method (22). In brief, purified monocytes were cultured in the presence or absence of the cytokines under study. At day 5, cells were harvested after $5 \mathrm{~min}$ incubation in $5 \mathrm{mM}$ EDTA by gentle scraping with a rubber policeman, and then washed and resuspended in RPMI supplemented with $20 \%$ FCS to a final concentration of $2 \times 10^{7}$ cells $/ \mathrm{ml}$. For each transfection, $10 \mu \mathrm{g}$ of each plasmid DNA was used. The long-terminal repeat-chloramphenicol acetyltransferase (LTR-CAT) construct and the SV-tat plasmid construct (a kind gift from Dr. A. B. Rabson, National Institute of Allergy and Infectious Diseases, Bethesda, MD) (23) were cotransfected to increase the level of CAT expression. The construct containing two nuclear factor (NF)-kB binding sites linked to the thymidine kinase promoter was a gift from Dr. Baltimore (Whitehead Institute, Boston, MA) (24). Before transfection, cells were placed on ice for $10 \mathrm{~min}$. Cells were electroporated in disposable cuvettes (Bio-Rad Laboratories, Richmond, CA) at $250 \mathrm{~V}$, $960 \mu \mathrm{F}$. After transfection, cells were placed on ice again for $10 \mathrm{~min}$, and then plated in a final concentration of $2 \times 10^{6} \mathrm{cells} / \mathrm{ml}$ in MDM medium, as described above. $24 \mathrm{~h}$ after transfection, cell extracts were prepared for CAT assay.

Proliferation assay. Cytokine-induced monocyte proliferation was determined in a 5-d assay. In brief, monocytes were cultured in the presence of the cytokine under study. At day 4 , cultures were pulsed with $7.3 \mathrm{kBq}\left[{ }^{3} \mathrm{H}\right]$ thymidine, and harvested after $18 \mathrm{~h}$.

PCR analysis. Analysis of the presence of proviral DNA sequences in inoculated monocytes was performed with a very sensitive "nested" polymerase chain reaction (PCR) method. Plasmid titrations have demonstrated that by use of this method, as few as two proviral DNA copies in a DNA equivalent of $5 \times 10^{5}$ cells can be detected (25). The PCR for amplification of the R/U5 region is less sensitive, and detects 100 1,000 proviral DNA copies in a DNA equivalent of $5 \times 10^{5}$ cells.

Monocytes were cultured for $5 \mathrm{~d}$ in the absence or presence of rIL-3 $(10 \mathrm{ng} / \mathrm{ml}), \mathrm{rlL}-4(50 \mathrm{ng} / \mathrm{ml})$, or a combination thereof. The inoculum (HIV-1 Ba-L) was DNase (200 ng/ml) (RQ1; Promega Corp., Madison WI) treated for $30 \mathrm{~min}$ in medium containing $6 \mathrm{mM} \mathrm{MgCl}_{2}$, and then filtrated through a $0.22-\mu \mathrm{m}$ filter. As a control, a heat-inactivated (HI$\mathrm{HIV} ; 1 \mathrm{~h}, 56^{\circ} \mathrm{C}$ ) inoculum was used. $24 \mathrm{~h}$ after inoculation, cells were carefully washed, and DNA was extracted from $10^{6}$ cells and finally solved in $100 \mu \mathrm{l}$ water. For each analysis, $5 \mu \mathrm{l}$ of the DNA solution was used in the first step of a two-step nested PCR (25), and $1 \mu$ l of the product of the first-step PCR is used in the second-step PCR. This results in the amplification of a conserved 125-bp sequence of the HIV1 pol region. $\mathrm{MgCl}_{2}$ concentrations are $1.5 \mathrm{mM}$ in the first step, and 1.0 $\mathrm{mM}$ in the second step. Primers used in the first step: 5TTA.GTC.AGT.GCT.GGA.ATC.AGG 3' (sense) and 5'GCT.ACA.TGA.ACT.GCT.ACC.AGG $3^{\prime}$ (antisense); in the second step: $5^{\prime}$ TTA.ACC.TGC.CAC.CTG.TAG.TAG.C $3^{\prime}$ (sense) and 5'ATG.TGT.ACA.ATC.TAG.TTG.CC $3^{\prime}$ (antisense). Amplification cycles of the first step: 5' 95 C once, then 1'30' 95 C, 2' 50 C, 2' 72 C, repeated 30 times; of the second step: $5^{\prime} 95 \mathrm{C}, 2^{\prime} 30^{\prime \prime} 25 \mathrm{C}, 1^{\prime} 30^{\prime \prime} 72 \mathrm{C}$ once, then $1^{\prime} 30^{\prime \prime} 95 \mathrm{C}, 1^{\prime}$ $37 \mathrm{C}, 2^{\prime} 72 \mathrm{C}$, repeated 30 times. Amplification of the 140-bp R/U5 fragment with primer pair M667 and AA55 (15) was performed identical to the amplification cycles of the first step in the pol amplification, also with $5 \mu$ l DNA solution.

Amplified DNA was separated on a polyacrylamide gel, blotted to Zeta-probe filter, and hybridized to an internal probe. For pol the 4373-bp to 4404-bp fragment was used; for the R/U5 the 9606-bp to 9631-bp fragment was used. PCR analysis of $\beta$-globine demonstrated the presence of DNA in all samples (data not shown).

\section{Results}

Inhibition of HIV-1 replication in primary infected monocytes. Highly purified peripheral blood monocytes were inoculated with HIV-1 Ba-L on days 0 to 5 of culture. Productive infection could only be demonstrated in monocytes inoculated after at least $2 \mathrm{~d}$ of culture (Fig. $1 \mathrm{a}$ ). Thus, differentiation induced by plastic adherence rendered monocytes susceptible to HIV-1 infection (2). Treatment with IL-4, an inducer of differentiation (26), resulted in accelerated susceptibility to HIV-1 infection, compared with untreated monocytes (Fig. $1 b$ ). However, complete resistance to HIV-1 infection was observed in monocytes

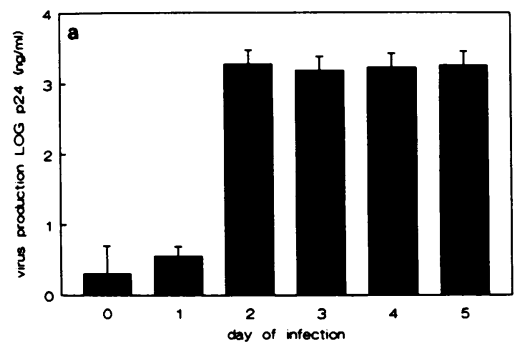

Figure 1. Time course of susceptibility for HIV-1 infection in fresh primary peripheral

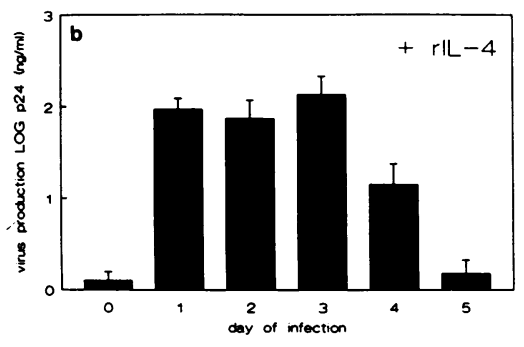
blood monocytes in the absence $(a)$ or presence of $(b) \mathrm{IL}-4(50 \mathrm{ng} / \mathrm{ml})$ Peak production at day 14 after inoculation is shown. Results are the mean of 12 replicates and representative for three independent experiments. 
that had been treated for $5 \mathrm{~d}$ with rIL-4. Apparently, accelerated differentiation induced by rIL-4 limits the susceptibility of monocytes for HIV-1 infection to a discrete window phase between day 1 and 5 of culture.

A dose-dependent inhibitory effect of 5-d rIL-4 treatment, with complete inhibition at a concentration of $50 \mathrm{ng} / \mathrm{ml}$, could be demonstrated (Fig. $2 a$ ). In order to confirm that the observed inhibition was due to IL-4 and not caused by a toxic contaminant in the preparation, rIL-4 was either heat inactivated for $30 \mathrm{~min}$ at $100^{\circ} \mathrm{C}$ (data not shown), or preincubated with a neutralizing anti-IL-4 serum (Fig. $2 b$ ) before addition to the cultures. In all experiments $(n=3)$, IL-4-induced inhibition of HIV-1 expression was completely abrogated in both protocols. IL- 4 had to be present during the first $5 \mathrm{~d}$ of culture to establish its inhibitory effect. Addition of IL-4 to the cultures at day 5, after inoculation, had no effect (data not shown). Furthermore, the inhibitory effect of IL-4 was cell-type specific, since virus production in PBL was enhanced by IL-4 (data not shown). Next to inhibition of HIV-1 production by rIL-4 of otherwise untreated MDM, the effect of this cytokine was analyzed in combination with cytokines known to enhance HIV expression in monocytes $(10,11,13)$. MDM pretreated with rIL-1, rIL-3, rGM-CSF, or rTNF- $\alpha$ showed enhanced HIV-1 expression, as compared with untreated controls. However, when these cytokines were used in combination with rIL-4, all cultures remained negative for virus production (Fig. 3).

Inhibition of productive HIV-1 infection is not caused by down modulation of CD4 expression. CD4, the receptor for HIV-1, is expressed at a very low level on MDM (27). FACS analysis demonstrated comparable low levels of CD4 expression on both 5-d cultured control cells and IL-4-treated cells (data not shown). Due to the very low expression, however, down modulation of CD4 by IL-4 as a mechanism of inhibition can hardly be quantified by analysis of membrane expression.

To further study whether IL-4 performs its inhibitory effect by down modulation of CD4 expression, mRNA levels for CD4 were compared for rIL-4-treated and untreated cells. No differences in the amounts of CD4-specific mRNA in treated or untreated cells were observed (Fig. $4 a$, lanes 1 and 2), other than due to differences in the total amount of mRNA (Fig. 4).

Furthermore, cells treated with combinations of rIL-4 and
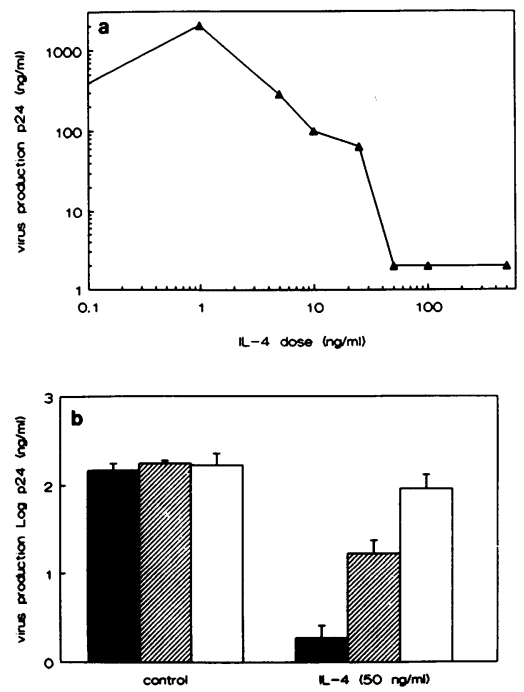

Figure 2. (a) Dose-dependent inhibition of HIV-1 infection by rIL4. Cells were cultured for $5 \mathrm{~d}$ in the presence of increasing doses rIL4. (b) Virus production after preneutralization of rIL-4 sample with an anti-IL-4 serum (dilutions of the anti-serum 1:10,000; 1:1,000; - no antiserum. Peak virus production on day 14 is given; results are the mean of 12 replicates and representative for three independent experiments.

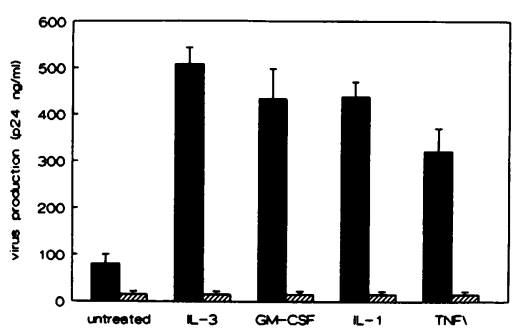

Figure 3. HIV-1 expression in monocytes pretreated with combinations of IL-4 and cytokines known to enhance HIV-1 expression. Peak virus production at day 14 is given. Results are the mean of 12 replicates and representative for four independent experiments. - control; - IL-4 $(50 \mathrm{ng} / \mathrm{ml})$.

rIL-1, rIL-3, rIL-6, GM-CSF, or TNF $\alpha$ also did not demonstrate any decrease in the level of CD4 mRNA (Fig. $4 a$, lanes 3-12):

Inhibition of productive HIV-1 infection occurs at a pretranscriptional level. Inhibitory effects of IL-4 on the expression of IL-6, IL-1, and TNF $\alpha$ in monocytes have been reported (28, 29). These cytokines induce activation of NF-kB $(30,31)$ or NF-kB-like factors. Since the expression of both HIV-1 (24) and these cytokines $(32,33)$ is believed to be predominantly regulated by NF-kB, we tested whether the mechanism of action by which rIL-4 inhibits HIV-1 expression was at the transcriptional level, in particular, by inhibition of NF-kB activation.

This was investigated in a transient expression system in which transcriptional activity under control of the HIV-1-LTR was studied. Pretreatment with either rIL-1, rIL-3, TNF $\alpha$, or rGM-CSF resulted in activation of the HIV-LTR. IL-4 did not inhibit LTR-driven CAT activity. On the contrary, the strongest induction of LTR-driven CAT activity was seen in MDM cultured with rIL-4 alone, or with combinations of IL-4 with other cytokines (Fig. $4 a$ ). Comparable results were obtained when the NF-kB-CAT construct was used, demonstrating that the HIV-1 LTR activity was associated with induction of NFkB (Fig. 4 b).

Since virus could not be rescued upon lysis of the IL-4treated HIV-1-inoculated MDM, the absence of productive infection was not due to intracellular accumulations of virions. Furthermore, Northern blot analysis of IL-4-pretreated, HIV$1 \mathrm{Ba}-\mathrm{L}$-inoculated monocytes revealed the complete absence of HIV-1 transcripts, indicating that the inhibition was at a pretranscriptional level (Fig. 5).

Inhibition of monocyte proliferation prevents $H I V-1$ infection. Previously, we and others demonstrated low levels of proliferation and HIV-1 replication in purified monocytes. Both effects could be augmented by pretreatment with rIL-3 or rGM-CSF $(10,14,34)$. Proliferation was not only detected by $\left[{ }^{3} \mathrm{H}\right]$ thymidine incorporation, but also by about a twofold increase in cell number in the course of the experiments (data not shown) (10). Since in T cells proliferation is a prerequisite for HIV-1 infection $(15,16)$, we studied to what extent the effect of IL-4 on productive HIV-1 infection of monocytes is proliferation dependent. Proliferative capacity of monocytes in the presence of either GM-CSF alone, or in combination with IL-4, was compared during the first $5 \mathrm{~d}$ of culture. In the absence of IL-4, proliferation could be demonstrated from day 2 on, reaching maximum levels at day 5 (Fig. $6 a$ ). In the presence of IL-4, comparable kinetics of the proliferative response were seen during the first $4 \mathrm{~d}$. However, probably as a result of in- 

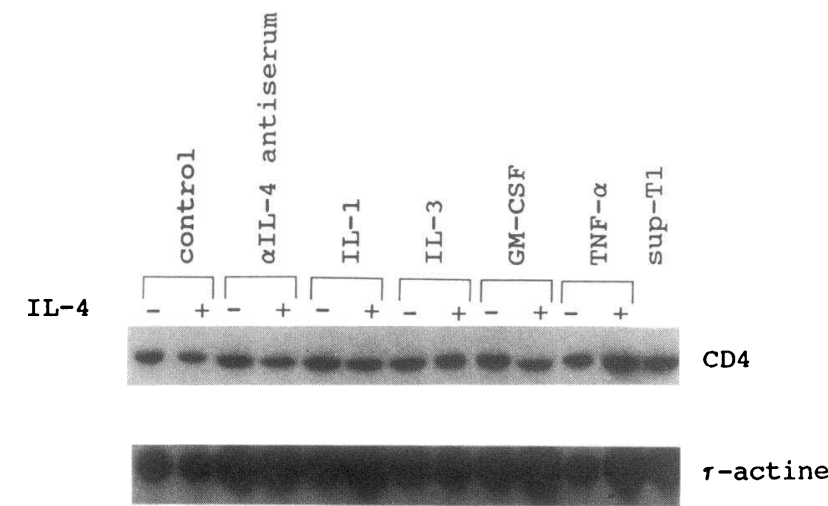

b

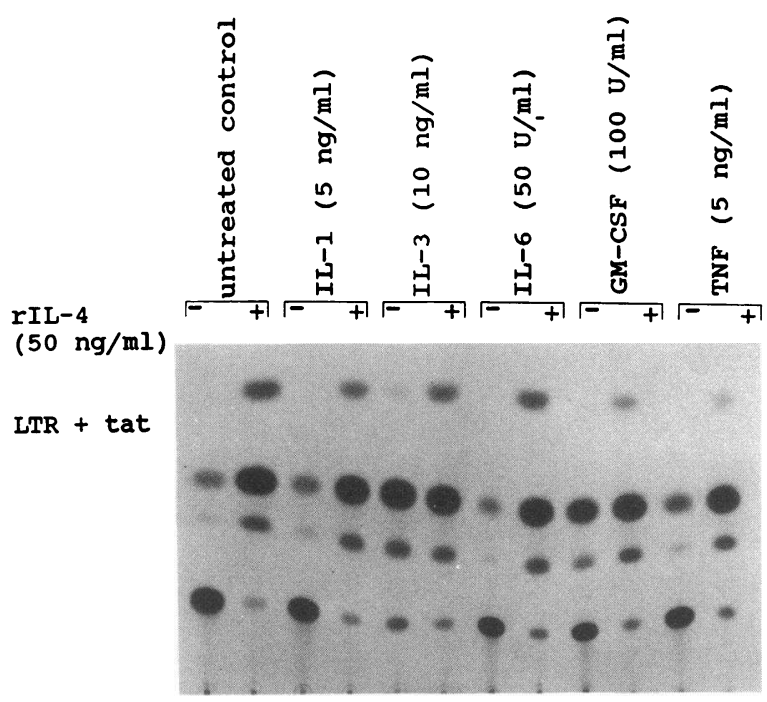

$\mathbf{N F}-\mathbf{k B}$

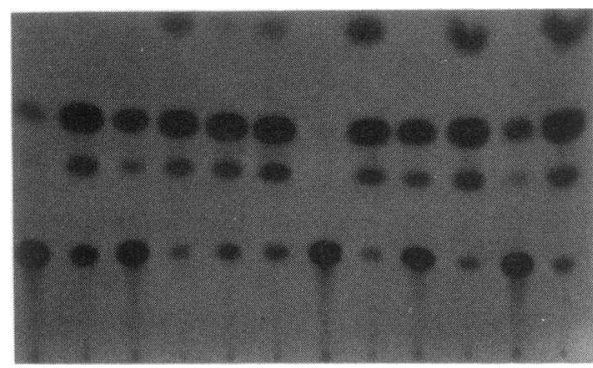

Figure 4. Analysis of effect of IL-4 on (a) CD4-mRNA expression and (b) HIV-1 LTR or NF-kB activity. Monocytes were cultured for $5 \mathrm{~d}$ in the presence of IL-1 $(5 \mathrm{ng} / \mathrm{ml}), \mathrm{IL}-3(10 \mathrm{ng} / \mathrm{ml})$, GM-CSF $(100 \mathrm{U} /$ $\mathrm{ml})$, TNF- $\alpha(5 \mathrm{ng} / \mathrm{ml})$, either alone or in combination with rIL-4 (50 $\mathrm{ng} / \mathrm{ml}$ ). Data represent three independent experiments. As a quantitative control for the total amount of RNA, a $\tau$-actin probe was used.

duction of terminal differentiation, a 5-d treatment of monocytes with rIL-4 resulted in complete inhibition of proliferation (Fig. 6 b). Similar results were obtained when IL-4 was used in combination with IL-3 (data not shown).

To analyze whether the inhibitory effect on both productive HIV-1 infection and proliferation was indeed due to the induction of terminal differentiation, other differentiation-in-
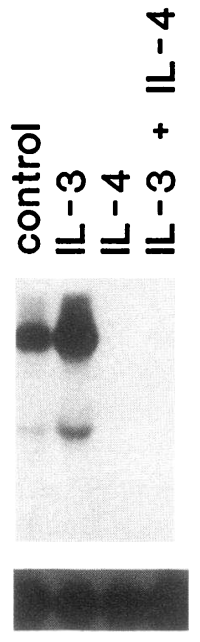

HIV-1 transcripts

$9.6 \mathrm{~Kb}$

$4.2 \mathrm{~Kb}$

gamma-actine
Figure 5. Analysis of HIV-1-specific mRNA transcripts in monocytes cultured for $5 \mathrm{~d}$ in the presence of IL- 4 ( 50 $\mathrm{ng} / \mathrm{ml}$ ) before inoculation. As a positive control, both untreated and IL-3- (10 ng/ml) treated monocytes were used. Isolation of mRNA was performed $2 \mathrm{~d}$ after inoculation. For the detection of HIV-1-specific transcripts, a mix of two probes corresponding to a fragment in the pol and env region were used. As a quantitative control for the total amount of RNA, a $\tau$ actin probe was used. ducing agents, dexamethasone (26) and $1,25(\mathrm{OH})_{2}$ vitamin $\mathrm{D}_{3}$ $\left(1,25(\mathrm{OH})_{2} \mathrm{D}_{3}\right)(35)$, were used. As observed with IL-4, a 5-d pretreatment of monocytes with either dexamethasone or $1,25(\mathrm{OH})_{2} \mathrm{D}_{3}$ resulted in the complete absence of proliferation and HIV-1 infection (Fig. 7 a), even when a combination with GM-CSF was used (Fig. 7 b).

The role of monocyte proliferation was further analyzed in a differentiation-independent fashion by use of the antimitotic agent mitomycin-C. A 30-min treatment with mitomycin-C of monocytes that had been precultured for $5 \mathrm{~d}$ resulted in complete inhibition of both proliferation and HIV-1 infection (Fig. 8). Prevention of HIV-1 infection by mitomycin-C treatment was effective until $24 \mathrm{~h}$ after inoculation, but not thereafter, suggesting a block early in the replication cycle (Fig. 7). Addition of mitomycin-C $48 \mathrm{~h}$ after inoculation had no effect, excluding toxic side effects of the drug. Comparable results were obtained when proliferation was blocked by gamma irradiation (5,000 rad; data not shown).
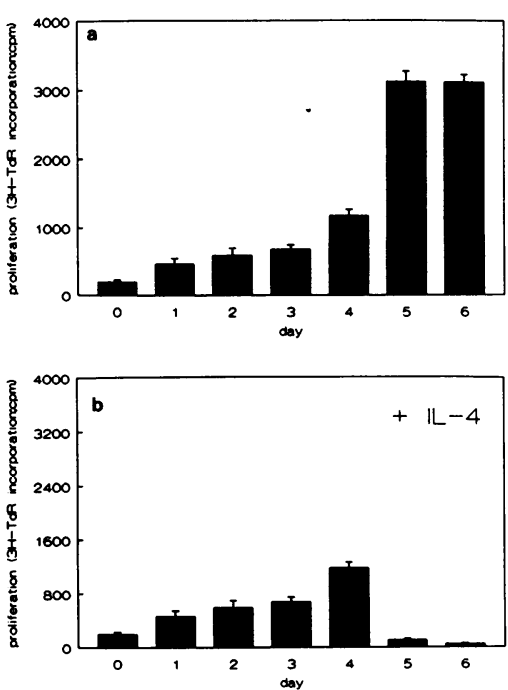

Figure 6. (a) Time capacity of monocytes in the presence of GM$\mathrm{CSF}(100 \mathrm{U} / \mathrm{ml})$, or $(b)$ in the presence of a combination of GMCSF with IL-4 (50 ng/ $\mathrm{ml})$. Results are the mean of 12 replicates and representative for two independent experiments. course of proliferative 

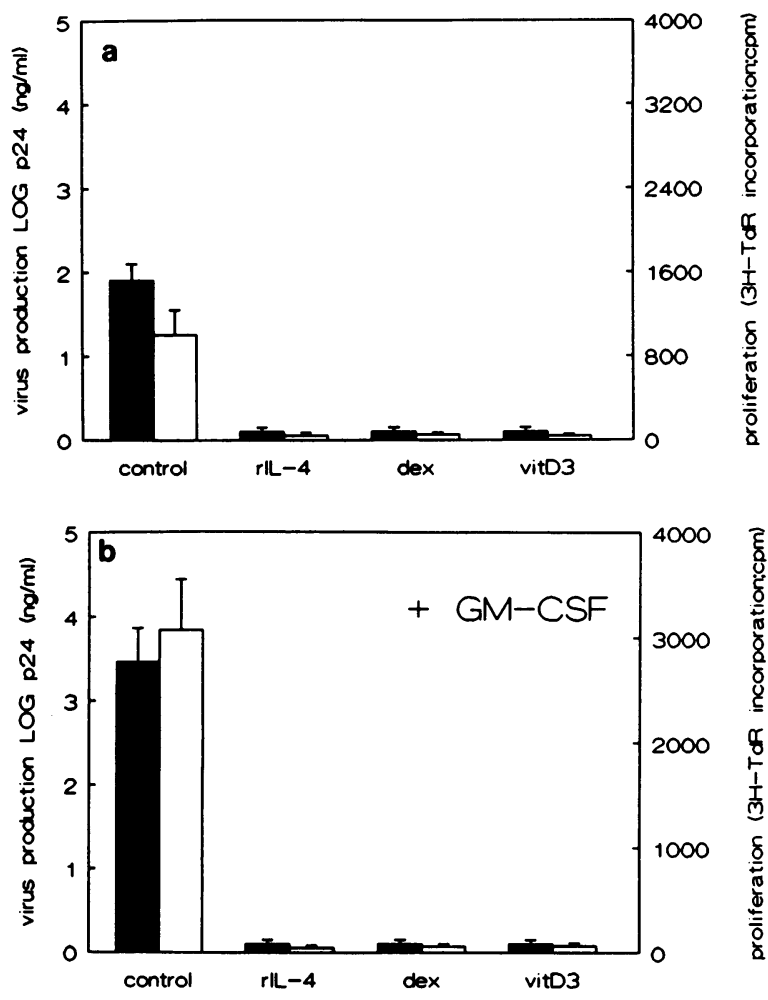

Figure 7. Analysis of susceptibility for productive HIV-1 infection and proliferative capacity in monocytes cultured for $5 \mathrm{~d}$ in the presence of differentiation-inducing agents IL-4 $(50 \mathrm{ng} / \mathrm{ml})$, dexamethasone $(10 \mathrm{ng} / \mathrm{ml})$ or $1,25(\mathrm{OH})_{2} \mathrm{D}_{3}(10 \mathrm{nM})$ alone, $(a)$, or in combination with GM-CSF $(b)$. Proliferation was determined at day 5 of culture, and peak virus production at day 14, after inoculation. Closed bars represent virus production (left $y$-axis), open bars represent proliferation (right $y$-axis). Results are mean of 12 replicates and representative for two independent experiments.

Incomplete proviral DNA species in nonproliferating MDM. Studies in quiescent $T$ cells have revealed that in the absence of proliferation only incomplete proviral DNA species are synthesized, indicating a normal entry, but defective reverse transcription in these cells (15). To investigate whether the replication block in nonproliferating macrophages was at a similar level, we performed PCR analysis using the primer pair M667/ AA55 specific for the R/U5 region of the LTR to analyze early steps in reverse transcription (15), and a primer pair specific for

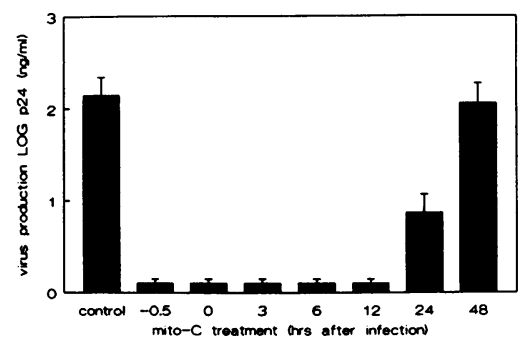

Figure 8. Time course of mitomycin-C treatment of 5-d cultured monocytes inoculated with HIV-1 Ba-L. Mitomycin-C $(25 \mu \mathrm{g} / \mathrm{ml})$ was added to the cultures, either $30 \mathrm{~min}$ before, or $3,6,12,24$, or $48 \mathrm{~h}$ after inoculation, and carefully washed after

30 min of incubation. Virus peak production at day 14 is shown. Results are mean of 12 replicates and representative for two independent experiments. Mitomycin-C-treated cells lacked proliferative capacity (data not shown). a region in the pol gene, reverse transcription of which occurs late in provirus formation. In nonproliferating macrophages inoculated with HIV-1 Ba-L, proviral DNA could not be detected with the primer pair specific for a fragment in the pol gene, indicating the absence of complete provirus (Fig. 9). However, amplification of the R/U5 region was successful, confirming the presence of incomplete DNA species (Fig. 9). Thus, similar to resting $T$ cells, in nonproliferating macrophages the block in the infection cycle is at the level of reverse transcription (15).

\section{Discussion}

In this study we investigated the cellular requirements for HIV1 infection in primary monocytes. The low frequency of HIV1-harbouring monocytes in the peripheral blood compartment (6), and the finding that macrophages are the predominantly infected cells in tissues suggests that monocytes become susceptible for HIV-1 infection relatively late in their ontogeny. This hypothesis was supported by the finding that freshly isolated
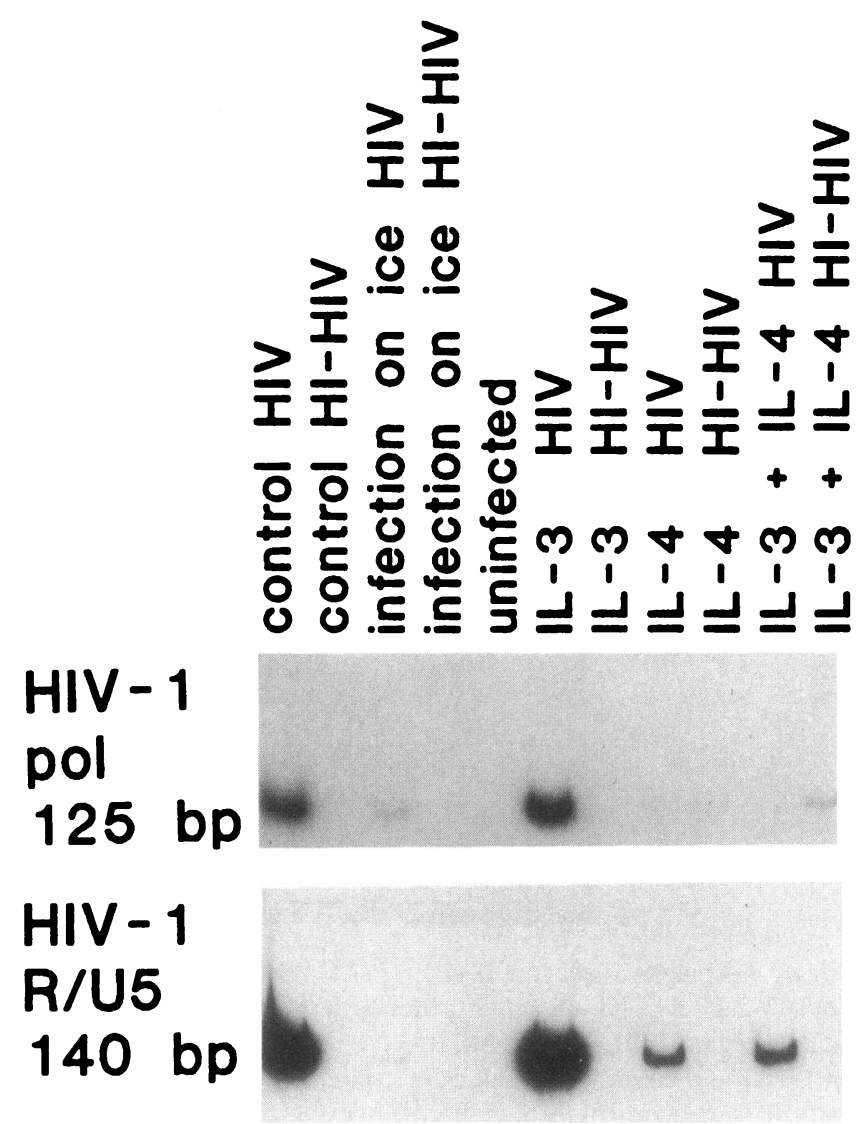

Figure 9. Analysis of proviral DNA species in IL-4-treated monocytes. Incomplete DNA species, represented by the amplified RU5 region, could be demonstrated in each group irrespective of the pretreatment, whereas amplification of the pol gene fragment was only successful in proliferating cells. Monocytes were cultured for $5 \mathrm{~d}$ in the absence or presence of rIL-3 $(10 \mathrm{ng} / \mathrm{ml})$ and/or rIL-4 $(50 \mathrm{ng} / \mathrm{ml})$. The inoculum was DNase ( $200 \mathrm{ng} / \mathrm{ml}$, Promega Corp.) treated for $30 \mathrm{~min}$ to distinguish for new synthesized proviral DNA. As a negative control, a heat-inactivated inoculum (HI-HIV; $1 \mathrm{~h}, 56^{\circ} \mathrm{C}$ ) was used. DNA was extracted $24 \mathrm{~h}$ after inoculation. 
monocytes were insusceptible for infection with HIV-1, whereas successful infection could be established after a 2-d culture, during which, most likely as a consequence of plastic adherence, differentiation is induced. Terminal differentiation induced by IL-4, dexamethasone, or $1,25(\mathrm{OH})_{2} \mathrm{D}_{3}$ resulted in complete resistance to HIV-1 infection, indicating that monocyte susceptibility to HIV-1 infection is limited to a rather discrete phase during differentiation. The course of the HIV-1 replication block in terminally differentiated macrophages was investigated. In IL-4-pretreated cells, enhanced LTR activity was seen in a transient expression system, predominantly associated with induction of NF-kB. HIV-1 inoculation of IL-4treated cells, however, resulted in the complete absence of HIV-1-specific transcripts, thus pointing to a pretranscriptional block in the virus replication cycle in IL-4-treated cells.

Previously, we and others demonstrated low levels of proliferation in monocytes that could be enhanced by the addition of IL-3 or GM-CSF $(10,14,34)$. IL-4 treatment of monocytes resulted in a complete proliferation block concomitant with the induction of differentiation. Recently, productive HIV-1 infection of $\mathrm{T}$ cells was shown to be proliferation dependent $(15,16)$. Here we demonstrated that differentiation-independent inhibition of proliferation by mitomycin-C treatment or irradiation also renders monocytes refractory to HIV-1 infection. Moreover, in complete analogy to quiescent T cells (15), in nonproliferating monocytes only incomplete DNA species could be demonstrated, indicating a block at the level of reverse transcription.

In quiescent $\mathrm{T}$ cells, the incomplete HIV-1 DNA structure is considered to be an intermediate latent form that can become activated upon subsequent stimulation of $\mathrm{T}$ cells. In these activated cells, reverse transcription might be completed, resulting in productive infection. In IL-4-treated terminally differentiated macrophages inoculated with HIV-1, neither proliferation nor virus production could be induced by treatment with IL-3 or GM-CSF (data not shown). Therefore, in contrast to resting $\mathrm{T}$ cells, the incomplete HIV-1 DNA species in macrophages probably represents a dead-end product, rather than a latent form.

These experiments demonstrate that the cellular requirements for HIV-1 infection of monocytes and T cells are remarkably similar, although the two cell types probably have very different roles in the pathogenic process underlying the progression to AIDS. HIV-1 infection in monocytes has been considered to be proliferation independent (1). Susceptibility for HIV-1 infection, however, decreases over time (36), as does the proliferative capacity of monocytes in culture (14). Here, due to enhanced terminal differentiation and concomitant with that, inhibition of proliferation, the period during which monocytes are susceptible to HIV-1, is limited to a brief window period during differentiation into macrophages. Differentiation of monocytes in vivo most likely occurs after diapedesis, and is modulated during inflammatory responses by cytokines such as IL- 4 or IL-6, which are released by activated T cells and monocytes, respectively. Intimate interaction between infected $T$ cells and differentiating monocytes at this stage may provide an efficient mechanism for HIV-1 transmission. Subsequently, upon terminal differentiation, these infected macrophages in turn may function as a reservoir for infection of $T$ cells. The high activity of NF-kB in these terminally differentiated macrophages thus creates the optimal conditions for efficient virus production. Interestingly, our data on proliferation-dependent HIV-1 infection in monocytes indicate that phagocytosis of HIV-1 particles or infected cells by mature macrophages will not result in productive HIV-1 infection.

Susceptibility for HIV-1 infection has been reported for a variety of cell types next to $T$ cells and cells of the monocyte/ macrophage lineage. Further study will have to reveal to what extent proliferative dependence is a feature of HIV-1 infection in these cell types.

\section{Acknowledgments}

We thank Drs. R. A. W. van Lier, P.Th.A. Schellekens and R. A. Gruters (ESN) for helpful discussions.

This study was supported in part by a grant from RGO/WVC (ministry of public health, 88005), and in part by a grant from the Netherlands organization for Scientific Research (88-93). F. Miedema is a senior fellow of the Royal Netherlands Academy of Arts and Sciences.

\section{References}

1. Gartner, S., P. Markovits, D. M. Markovits, M. H. Kaplan, R. C. Gallo, and M. Popovic. 1986. The role of mononuclear phagocytes in HTLV-III/LAV infection. Science (Wash. DC). 233:215-219.

2. Gendelman, H. E., J. M. Orenstein, M. A. Martin, C. Ferrua, R. Mitra, T. Phipps, L. A. Wahl, H. C. Lane, A. S. Fauci, D. S. Burke, et al. 1988. Efficient isolation and propagation of human immunodeficiency virus on recombinant colony-stimulating factor 1-treated monocytes. J. Exp. Med. 167:1428-1441.

3. Popovic, M., and S. Gartner. 1987. Isolation of HIV-1 from monocytes but not T lymphocytes. Lancet. 916.

4. Schuitemaker, H., N. A. Kootstra, R. E. Y. De Goede, F. De Wolf, F. Miedema, and M. Tersmette. 1991. Monocytotropic Human Immunodeficiency Virus 1 (HIV-1) variants detectable in all stages of HIV infection predominantly lack T-cell line tropism and syncytium-inducing ability in primary $\mathrm{T}$-cell culture. J. Virol. 65:356-363.

5. Gendelman, H. E., J. M. Orenstein, L. M. Baca, B. Weiser, H. Burgers, D. C. Kalter, and M. S. Meltzer. 1989. The macrophage in the persistence and pathogenesis of HIV infection. Editorial review. AIDS (Phila.). 3:475-495.

6. Schnittman, S. M., M. C. Psallidopoulos, H. C. Lane, L. Thompson, M. Baseler, F. Massari, C. H. Fox, N. P. Salzman, and A. S. Fauci. 1989. The reservoir for HIV-1 in human peripheral blood is a T cell that maintains expression of CD4. Science (Wash. DC). 245:305-308.

7. Von Laer, D., F. T. Hufert, T. E. Fenner, S. Schwander, M. Dietrich, H. Schmitz, and P. Kern. 1990. CD34 ${ }^{+}$hematopoietic progenitor cells are not a major reservoir of the human immunodeficiency virus. Blood. 76:1281-1286.

8. McElrath, M. J., R. M. Steinman, and Z. A. Cohn. 1991. Latent HIV-1 infection in enriched populations of blood monocytes and $T$ cells from seropositive patients. J. Clin. Invest. 87:27-30.

9. Kitano, K., G. C. Baldwin, M. A. Raines, and D. W. Golde. 1990. Differentiating agents facilitate infection of myeloid leukemia cell lines by monocytotropic HIV-1 strains. Blood. 76:1980-1988.

10. Koyanagi, Y., W. A. O'Brien, J. Q. Zhao, D. W. Golde, J. C. Gasson, and I. S. Y. Chen. 1988. Cytokines alter production of HIV-1 from primary mononuclear phagocytes. Science (Wash. DC). 241:1673-1675.

11. Kornbluth, R. S., P. S. Oh, J. R. Munis, P. H. Cleveland, and D. D. Richman. 1989. Interferons and bacterial lipopolysaccharide protect macrophages from productive infection by human immunodeficiency virus in vitro. $J$. Exp. Med. 169:1137-1151.

12. Fauci, A. S. 1988. The human immunodeficiency virus: infectivity and mechanisms of pathogenesis. Science (Wash. DC). 239:617-622.

13. Poli, G., P. Bressler, A. Kinter, E. Duh, W. C. Timmer, A. Rabson, J. S. Justement, S. Stanley, and A. S. Fauci. 1990. Interleukin 6 induces human immunodeficiency virus expression in infected monocytic cells alone and in synergy with tumor necrosis factor $\alpha$ by transcriptional and post-transcriptional mechanisms. J. Exp. Med. 172:151-158.

14. Schuitemaker, H., N. A. Kootstra, M. Van Oers, R. Van Lambalgen, M. Tersmette, and F. Miedema. 1990. Induction of monocyte proliferation and HIV expression by IL-3 does not interfere with anti-viral activity of zidovudine. Blood. 76:1490-1493.

15. Zack, J. A., S. J. Arrigo, S. R. Weitsman, A. S. Go, A. Haislip, and I. S. Y. Chen. 1990. HIV-1 Entry into quiescent primary lymphocytes: Molecular analysis reveals a labile, latent viral structure. Cell. 61:213-222. 
16. Stevenson, M., T. L. Stanwick, M. P. Dempsey, and C. A. Lamonica. 1990. HIV-1 replication is controlled at the level of $\mathrm{T}$ cell activation and proviral integration. EMBO (Evr. Mol. Biol. Organ.) J. 9:1551-1560.

17. Figdor, C. G., W. S. Bont, I. Touw, J. De Roos, E. E. Roosnek, and J. De Vries. 1982. Isolation of functionally different human monocytes by counterflow centrifugation elutriation. Blood. 60:46-54.

18. Tersmette, M., I. N. Winkel, M. Groenink, R. A. Gruters, P. Spence, E. Saman, G. van der Groen, F. Miedema, and J. G. Huisman. 1989. Detection and subtyping of HIV-1 isolates with a panel of characterized monoclonal antibodies to HIV-p24gag. Virology. 171:149-155.

19. Brakenhoff, J. P. J., E. R. De Groot, R. F. Evers, H. Pannekoek, and L. A. Aarden. 1987. Molecular cloning and expression of hybridoma growth factor in Escherichia coli. J. Immunol. 139:4116-4121.

20. Dorssers, L., H. Burger, and F. Bot. 1987. Characterization of a human multi-lineage colony stimulating factor cDNA clone identified by a conserved non coding sequence in mouse interleukin-3. Gene (Amst.). 55:115-124.

21. Santoli, D., Y-C. Yang, S. C. Clark, B. L. Kreider, D. Caracciolo, and G. Rovera. 1987. Synergistic and antagonistic effects of recombinant human Interleukin (IL) 3, IL-1a, granulocyte and macrophage colony stimulating factors (G-CSF, M-CSF) on the growth of GM-CSF dependent leukemic cell lines. $J$. Immunol. 139:3348-3354.

22. Cann, A. J., Y. Koyanagi, and I. S. Y. Chen. 1988. High efficiency transfection of primary human lymphocytes and studies of gene expression. Oncogene. 3:123-128.

23. Gimble, J. M., E. Duh, J. M. Ostrove, H. E. Gendelman, E. E. Max, and A. B. Rabson. 1988. Activation of the human immunodeficiency virus long terminal repeat by herpes simplex virus type 1 is associated with induction of a nuclear factor that binds to the NF-kappaB/core enhancer sequence. J. Virol. 62:4104 4112.

24. Nabel, G., and D. Baltimore. 1987. An inducible transcription factor activates expression of human immunodeficiency virus in T cells. Nature (Lond.). 326:711-713.

25. Bruisten, S. M., M. H. G. M. Koppelman, C. L. Van der Poel, and J. G. Huisman. 1991. Enhanced detection of HIV-1 sequences using PCR and a liquid hybridization technique. Vox Sang. 61:24-29.
26. Te Velde, A. A., J. P. G. Klomp, B. A. Yard, J. E. De Vries, and C. G. Figdor. 1988. Modulation of phenotypic and functional properties of human peripheral blood monocytes by IL-4. J. Immunol. 140:1548-1554.

27. Collman, R., B. Godfrey, J. Cutilli, A. Rhodes, N. F. Hassan, R. Sweet, S. D. Douglas, H. Friedman, N. Nathanson, and F. Gonzalez-Scarano. 1990 Macrophage-tropic strains of human immunodeficiency virus type 1 utilize the CD4 receptor. J. Virol. 64:4468-4476.

28. Essner, R., K. Rhoades, W. H. McBride, D. L. Morton, and J. S. Economou. 1989. IL-4 down-regulates IL-1 and TNF gene expression in human monocytes. J. Immunol. 142:3857-3861.

29. Te Velde, A. A., R. J. F. Huijbens, K. Heije, J. E. De Vries, and C. G. Figdor. 1990. Interleukin-4 (IL-4) inhibits secretion of IL-1 $\beta$, tumor necrosis factor $\alpha$, and IL-6 by human monocytes. Blood. 76:1392-1397.

30. Osborn, L., S. Kunkel, and G. J. Nabel. 1989. Tumor necrosis factor $\alpha$ and interleukin 1 stimulate the human immunodeficiency virus enhancer by activation of the nuclear factor kappaB. Proc. Natl. Acad. Sci. USA. 86:2336-2340.

31. Duh, E. J., W. J. Maury, T. M. Folks, A. S. Fauci, and A. B. Rabson. 1989. Tumor necrosis factor $\alpha$ activates human immunodeficiency virus type 1 through induction of nuclear factor binding to the NF-kappaB sites in the long terminal repeat. Proc. Natl. Acad. Sci. USA. 86:5974-5978.

32. Lenardo, M. J., and D. Baltimore. 1989. NF-kB: A pleiotropic mediator of inducible and tissue-specific gene control. Cell. 58:227-229.

33. Shakhov, A. N., M. A. Collart, P. Vassalli, S. A. Nedospasov, and C. V. Jongeneel. 1990. kB-type enhancers are involved in lipopolysaccharide-mediated transcriptional activation of the tumor necrosis factor $\alpha$ gene in primary macrophages. J. Exp. Med. 171:35-47.

34. Kitano, K., C. N. Abboud, D. H. Ryan, S. G. Quan, G. C. Baldwin, and D. W. Golde. 1991. Macrophage-active colony-stimulating factors enhance human immunodeficiency virus type 1 infection in bone marrow stem cells. Blood. 77:1699-1705.

35. Kreutz, M., and R. Andreesen. 1990. Induction of human monocyte to macrophage maturation in vitro by 1,25-dihydroxyvitamin D3. Blood. 76:24572461.

36. Potts, B. J., W. Maury, and M. A. Martin. 1990. Replication of HIV-1 in primary monocyte cultures. Virology. 175:465-476. 